\title{
A PORNOGRAFIA COMO LIBERTAÇÃO: RESISTÊNCIA AOS CONSTRUTOS DE GÊNERO NA NARRATIVA DAS PERSONAGENS GLAUCO MATTOSO E JOE
}

\author{
Diego Ravarotto da Costa ${ }^{1}$ \\ Luciana Paiva Coronel ${ }^{2}$
}

\begin{abstract}
Resumo: O presente trabalho visa analisar a obra lírica do autor brasileiro Glauco Mattoso, com ênfase nos sonetos que apresentam elevado teor autobiográfico, buscando, a partir dessa análise, contrastar as características do eu lírico do personagem Glauco Mattoso com aquelas da personagem Joe, protagonista de Ninfomaníaca (2014), longa metragem escrito e dirigido pelo cineasta dinamarquês Lars von Trier. Partindo dessas vozes, uma do gênero masculino e outra do gênero feminino, objetivamos a identificação de características em suas personalidades que divergem daquelas ditadas pelos construtos de gênero referentes à sociedade atual. Para ambos, essas características divergentes encontram-se no papel que desempenham em suas relações sexuais: Glauco, masoquista e podólatra, encontra-se em uma posição de submissão durante o ato sexual; Joe, por outro lado, além de assumir sua sexualidade - atitude polêmica quando desempenhada por uma mulher -, também assume posição dita masculina em suas relações, não só sexuais, como amorosas, ao ser dominadora. Tais características, portanto, servem de resistência aos ditames de gênero, contrariando-os e insistindo que ao gênero está imbricada a fluidez. Quanto ao aporte teórico da pesquisa, levamos em consideração os escritos de Lauretis (1987), Figueiredo (2013) e Maingueneau (2010).
\end{abstract}

Palavras-chave: Glauco Mattoso. Lars von Trier. Ninfomaníaca. Gênero.

Abstract: This essay aims at analyzing the poetry of Brazilian author Glauco Mattoso with emphasis on the sonnets that present a great level of autobiographical content, so that it allows us to later compare the characteristics of the character Glauco's lyric self to those of Joe, protagonist of the movie Nymphomaniac (2014), written and directed by Danish filmmaker Lars von Trier. By taking into account these characters and their speeches, one of them being a male and the other a female, we shall identify on them characteristics which diverge from those dictated by the gender roles found in our society. For both of them, these characteristics appear clearer when analyzing moments that comprehend their role in sexual intercourses. Being a masochist and a foot fetishist, Glauco assumes a submissive role in relation to its partner while Joe, on the other hand, besides assuming her own sexuality which is a sensitive topic involving women, also assumes a dominant role, which is commonly considered a position strictly occupied by men. That being said, these characteristics serve as resistance, seeing as they directly oppose what is preconceived in terms of gender, admitting its fluid nature. As for the theoretical framework, we are taking into account the studies developed by Lauretis (1987), Figueiredo (2013), and Maingueneau (2010).

Keywords: Glauco Mattoso. Lars von Trier. Nymphomaniac. Gender.

\footnotetext{
${ }^{1}$ Graduando em Letras - Português e Inglês pela Universidade do Rio Grande - FURG. E-mail: ravarottodiego@hotmail.com.

${ }^{2}$ Doutora em Literatura Brasileira pela Universidade de São Paulo - USP e coordenadora do projeto de pesquisa "Vozes marginais na literatura brasileira dos anos 60 ao presente".
} 


\section{Introdução}

A resistência pode se manifestar de maneiras diversas em diferentes mídias, muitas das vezes denotando uma afronta a algo que se torna norma ou préestipulado em uma sociedade. Portanto, pode ser evidenciada, no caso do autor e do cineasta cujas obras são o foco central dessa pesquisa, no confronto que travam com os constructos de gênero e sexualidade.Ademais, a resistência pode ser evidenciada ao ser o tema da narrativa, como se pôde observar na grande maioria da literatura escrita durante o período ditatorial brasileiro - período bastante fecundo para a literatura de Glauco Mattoso -, ou ao ser um aspecto imanente à escrita (BOSI, 2002, p. 18-22), como exemplificado na grande maioria das narrativas trazidas pelo movimento Dogma 95, idealizado por Lars von Trier e Thomas Vinterberg.

Sendo assim, permitir, através desta pesquisa, um contraste entre a obra do autor brasileiro Glauco Mattoso e a narrativa cinematográfica trazida por Lars von Trier em Ninfomaníaca (2014) surge como uma oportunidade de intensificar o trabalho já alicerçado sobre as questões de gênero e sexualidade presentes nos escritos do primeiro,adicionando ao mesmo o peso e densidade contemplativa trazida pelo segundo. Sendo assim, é deste ponto catalisador que a pesquisa em questão se origina: a capacidade de ambos autores em introduzir, no caso de Trier com um alcance um tanto maior, ao seu público temáticas tais como a de gênero e sexualidade de maneira a partirem com as preconcepções acerca desses tópicos, responsáveis por ditar uma grande parte da vida em sociedade e os comportamentos aceitáveis aos olhos da mesma, sendo eles diferentes para homens e mulheres.

Portanto, ao iniciar este artigo, daremos vazão, primeiramente, às contribuições desse autor e desse cineasta para as discussões a serem construídas na sequência. Trataremos brevemente dos planos de fundo que os permitiram construir e exibir tais conceitos, como o movimento Dogma 95, que impulsionou Trier, e o período ditatorial brasileiro, profícuo para Mattoso. Ademais, falaremos daqueles que serão os pontos cardeais que guiarão a análise e comparação trazida por esse artigo: as narrativas dos personagens Glauco Mattoso e Joe. 
No item seguinte, trataremos de explicitar as ideias, pensamentos, conjeturas e observações tecidas acerca das questões de gênero por estudiosos da área, construindo, assim, o trançado de informações necessário para a subsequente análise e comparação das narrativas.

Consequentemente, realizaremos, logo em seguida, um trabalho de análise e comparação entre a narrativa de caráter autobiográfico da personagem Joe de Ninfomaníaca (2014) e a informação encontrada em sonetos de alto teor autobiográfico de Glauco Mattoso e que apresentam como protagonista e eu lírico o personagem homônimo. A partir dessa análise, traçaremos similaridades entre a narrativa masculina, a de Glauco, e a narrativa feminina, a de Joe, que, ao se interpelarem, revelam uma quebra dos construtos de gênero ao apresentarem um homem ocupando posições ditas femininas e vice-versa.

Em um último momento, concluindo esse artigo, passaremos a um momento de (re)coleta das conjunturas até então feitas e reiteraremos a intenção desse autor e desse cineasta em promoverem um desvio do que é normativo e pré-estabelecido na sociedade, proporcionando, de tal maneira, um espaço que cede voz àqueles que a perderam, aos misfits e desajustados, àqueles subjugados por apresentarem características tidas como anormais frente às formas que se negam a preencher.

\section{2. $O$ corpus da pesquisa e sua validade}

O corpus da pesquisa em questão constitui-se da obra Pegadas Noturnas (2004), um compêndio de sonetos escritos pelo autor paulistano Glauco Mattoso, e do longa-metragem Ninfomaníaca (2014), escrito e dirigido pelo cineasta dinamarquês Lars von Trier.

\subsection{Glauco Mattoso e os escritos das margens}

Profícuo durante os anos 70 e polêmico até os dias de hoje, Pedro José Ferreira da Silva adotou o pseudônimo Glauco Mattoso imaginando poder, através dele, ver a situação na qual se encontrava - ter contraído o glaucoma que viria a cegá-lo no futuro - com cores menos acinzentadas, além de homenagear um de seus escritores favoritos e grande inspiração para os seus escritos, Gregório de Mattos.

Um autor marginal, à primeira vista, porém, após a leitura de seus escritos, é 
fácil entender a escolha do próprio em denominar-se como um escritor maldito. Adepto da poesia satírico-fescenina, Mattoso é conhecido por seu humor ácido e sem regras, além do conteúdo de seus sonetos estar geralmente atrelado aos fetiches mais abominados pela sociedade: sadismo, masoquismo, coprofagia, etc. (PINTO, 2010, p. 48-49). Com um vocabulário chulo, Mattoso preenche a métrica de seus sonetos impecáveis e cumpre com seu objetivo: quebrar com o convencional sem fugir das regras, sem transparecer e/ou panfletar sua afronta.

Quanto ao início de sua trajetória como escritor, remontamos aos anos 70, durante os quais, segundo o próprio Mattoso, enfrentávamos um período de "resistência cultural contra uma ditadura com censura muito forte [...] E aí eu afirmava uma estética da pornografia, que obviamente não teria espaço para sair publicada por uma grande editora ou na imprensa" (CAIXETA, 2014, p. 237-238).

Membro integrante da "geração mimeógrafo", não demorou muito para que Glauco se tornasse um sinônimo de marginalidade, seja pelo vocabulário utilizado em seus sonetos, linguagem tida como pouco "literária" por dedicar-se ao experimentalismo de vanguarda; seja pela editoração simplória de suas obras, motivo que rendeu o título de "geração mimeógrafo" a ele e a outros autores do período; seja pela inserção de personagens tidos como marginais em suas narrativas, como a prostituta, o homossexual, o negro, o caboclo, o sertanejo, e outras minorias rechaçadas pela sociedade brasileira da época (MATTOSO, 1981, p. 20).

Com uma mescla entre marginalidade e erudição, Glauco Mattoso conseguiu criar obras que o tornaram não só marginal frente aos leitores para quem a sua literatura era uma novidade, como também em meio aos outros autores marginais. Utiliza-se de uma das estruturas líricas mais canônicas, o soneto, e de um vocabulário arcaico que carrega estruturas silábicas já desconhecidas para o falante da língua portuguesa atual, porém, nesse vocabulário encaixa termos tidos como chulos.

A resistência na obra de Glauco Mattoso, portanto, encontra-se nessas características que carrega. Ao trazer para o primeiro plano indivíduos cuja existência a sociedade evita reconhecer e fazer uso de um vocabulário considerado chulo ao escrever em uma estrutura tão prezada e canônica como o soneto, sua literatura acaba, assim, por proporcionar ao seu leitor "uma experiência out of joint: 
um tanto deslocada, mas que também incomoda (ALVES apud MATTOSO, 2004, p. $11)$.

Paradoxal, a escrita de Glauco Mattoso ainda causa alvoroço por seu conteúdo, no entanto, ao ultrapassar o véu da superficialidade gráfica de seus sonetos, podemos encontrar críticas sociais nas mãos desses personagens escabrosos, além de narrativas repletas de indivíduos que não se deixam adequar aos perfis pré-estabelecidos. Nos sonetos de Mattoso, homens e mulheres ganham uma chance de se deixarem ser sem amarras, sem ordem alguma para se retraírem ou impedirem seu florescer, e é nesses sonetos em questão que encontramos grande parte da sua crítica aos ditames de gênero.

No entanto, para essa pesquisa em questão, o foco não decaíra sobre os seus personagens libertários. Decaíra, porém, sobre o personagem principal desse movimento de desconformidade: o próprio Glauco Mattoso. Uma vez pseudônimo, transmutado em eu lírico, Glauco logo se tornou "uma criação de cunho artístico, de personagem literário (CAIXETA, 2014, p. 245).

Sendo assim, ao analisar o compêndio trazido em Pegadas Noturnas (2004), deparamo-nos com sonetos que carregam em si um alto teor autobiográfico e encontram-se encharcados de subjetividade. Escritos em primeira pessoa, contam causos referentes à infância, adolescência e maturidade desse personagem, eu lírico, pseudônimo, heterônimo e alter ego de Pedro José Ferreira da Silva. É a partir desses sonetos específicos que costuraremos a trajetória de Glauco, apontando na mesma o modo como as características desse personagem masculino vão de encontro aos ditames de gênero, proporcionando sua quebra.

\subsection{Lars von Trier e o Dogma 95}

Conhecido por realizar o que podemos conceber como "cinema pela provocação", o cineasta dinamarquês Lars von Trier logo se tornou famoso por longas-metragens cujos temas poucos se atreveriam a tratar. Cenas de estupro, mutilação de órgãos genitais e sexo explícito são alguns dos tópicos que geralmente se veem conectados a esse polêmico roteirista. Porém, poucos reconhecem o pano de fundo desses ideais, originado em conjunto com o também cineasta Thomas Vinterberg, em março de 1995, na Dinamarca.

Nascia, portanto, o Dogma 95. Seu objetivo: contestar tudo aquilo que o 
cinema da época passara a representar. Buscavam, portanto, "um 'cinema puro', que não fosse realizado com milhões em investimento, não estivesse sujeito às regras do capital, e não privilegiasse elementos como efeitos especiais, em detrimento do conteúdo de uma história" (PITTA, 2014, p. 89).

$O$ interesse puramente financeiro que influenciava o cinema da época e que era imensamente impulsionado pelo mercado e a indústria cinematográficas então vigentes eram grandes inimigos de tudo proposto pelo Dogma 95. Planejavam vencer a superficialidade que dominava as obras cinematográficas daquele momento ao provar que produções de conteúdo e com tramas e personagens interessantes poderiam, sim, serem criadas, sem serem necessárias grandes produções e/ou gastos. Sendo assim, a partir desse momento, estipularam-se as regras do movimento Dogma 95.

O "voto de castidade", como o intitularam, instituía dez regras primárias para as produções a serem alicerçadas em nome do movimento. Essas regras incluíam, em suma, a proibição do uso de qualquer instrumento que não fosse a câmera, e o uso obrigatório de cenário externos, sem que nada pudesse ser construído em prol da filmagem. O mesmo se aplicava ao uso de iluminação que não fosse a natural, apoios para a câmera que não fossem as mãos e trilhas sonoras que não fizessem parte do plano de fundo do ambiente em que se estava gravando a cena. Ademais, o filme deveria ser em tempo real e não deveria incluir ações "superficiais", como o homicídio.

Por fim, o nome do diretor não deveria constar no longa-metragem, visto que um dos objetivos do movimento era permitir que o filme falasse por si só, sem o peso - e valor - que o nome de seu diretor lhe imbuía. Daremos especial atenção as últimas palavras presentes nesse "voto de castidade", bastante importantes para introduzir o longa-metragem o qual estaremos analisando nesse artigo.

Além disso, juro como diretor, renunciar a meu gosto pessoal. Não sou mais um artista. Eu juro renunciar à criação de uma obra, já que considero o instante mais importante que o todo. Meu objetivo supremo é arrancar a verdade de meus personagens cenários. Prometo fazê-lo por todos os meios à minha disposição e ao custo de qualquer bom gosto e considerações estéticas. Portanto, faço aqui o meu voto de castidade (PITTA, 2014, p. 91).

Ao escrever e dirigir Ninfomaníaca (2014) e permitir que a personagem Joe 
contasse sua história ao seu interlocutor, Seligman, Trier levou adiante sua promessa. Apesar desse longa-metragem não figurar como um filme feito em nome do Dogma 95, como foi com Os ldiotas (1998), ele consegue representar com destreza o objetivo de Trier em arrancar a verdade de seus personagens e fazê-lo ao custo de qualquer bom gosto e considerações estéticas.

Em um filme que se passa no claustro do quarto de Seligman, senhor que resgata Joe do beco onde se encontrava machucada e suja, somos apresentados à essa personagem misteriosa cujo passado desconhecemos e que decide por contar sua história a esse senhor.

Um dos objetivos de Trier era trazer à tela a trajetória de uma personagem ninfomaníaca, geralmente caracterizada como tendo um apetite sexual excessivo e/ou um desejo compulsivo por sexo. Portanto, necessitava, ao fazê-lo, visto que tinha como objetivo um "cinema puro", sem amarras ou restrições, de apresentar cenas que caracterizassem essa ninfomania, isto é, cenas de sexo cruas e realistas.

Trier teve, assim, como único prejuízo dessa ideia libertadora, seu trabalho tachado como "pornográfico", situação que rende à Ninfomaníaca (2014) um dos motivos pelos quais é válido para a discussão acerca da resistência. Apesar do termo "pornográfico" perder seu tom pejorativo na academia, tornando-se uma categoria de análise como qualquer outra, é no meio social que esse juízo de valor toma sua forma verdadeira. Portanto, apesar da aceitação em certos meios, "não devemos esquecer que, por natureza, a literatura pornográfica está destinada a proibição (MAINGUENEAU, 2010, p. 15)", o que lhe torna um símbolo de resistência por simplesmente ser capaz de ocupar esses meios, mesmo que em raras ocasiões.

A sexualização da personagem Joe não se apresenta aqui como uma tentativa de diminuí-la ao posto de objeto sexual, mas sim assegura a construção de sua personalidade e edifica seu posto de ninfomaníaca, visto que muitas dessas cenas tidas como obscenas são momentos-chave do filme que servem para estruturar grande parte da psique de Joe, o que, inclusive, contribui para a decisão que a mesma toma nos últimos minutos do longa.Por fim, será em sua narrativa autobiográfica que encontraremos uma conexão com o que também pode ser identificado na narrativa do personagem Glauco: a quebra dos ditames de gênero.

\section{Os ditames de gênero}


Enraizados em nossa sociedade, os ditames de gênero estão presentes em nossas vidas desde o nascimento. Com a descoberta do sexo do bebê que está por vir, o casal já inicia a compra de um enxoval que pensam carregar a cor, azul ou rosa, que caracteriza esse mesmo sexo, cuja relação com o gênero não é direta, muito menos estrita. Portanto, ao apresentarem genitais masculinos ou femininos, esses bebês passarão, durante esses primeiros anos de sua existência e os próximos que virem, a serem ensinados "pelo pai, mãe, família, escola, mídia, sociedade em geral, diferentes modos de pensar, de sentir, de atuar" (CABRAL e DíAZ, 1998, p. 1), desde que esses modos condigam com o esperado.

[...] as meninas são incentivadas a serem passivas, sensíveis, frágeis, dependentes e todos os brinquedos e jogos infantis reforçam o seu papel de mãe, dona de casa, e consequentemente responsável por todas as tarefas relacionadas ao cuidado dos filhos e da casa. Ou seja, as meninas brincam de boneca, de casinha, de fazer comida, de limpar a casa, tudo isto dentro do lar. Pelo contrário, os meninos brincam em espaços abertos, na rua. Eles jogam bola, brincam de carrinho, de guerra, etc. [...] Ninguém os manda arrumarem a cama, ou lavarem a louça, eles são incentivados a serem fortes, independentes, valentes" (CABRAL e DÍAZ, 1998, p. 1).

Durante a vida adulta, aos homens são associadas características como a "liderança, força, coragem e independência; às mulheres, os traços de dependência, cooperação, afetividade e lealdade (SCHULTZ, 2010, p. 3)". Por muito tempo, nem mesmo se cobrou dos homens traços tais como a da fidelidade ou $O$ comprometimento do mesmo com a monogamia, visto que o papel da lealdade se via presente na constituição do ser do gênero feminino. O mesmo se via presente na proibição dos homens em esboçar qualquer traço de afetividade ou sensibilidade, visto que essa não era uma característica do ser do gênero masculino, mas sim do feminino.

Os personagens aqui analisados quebram com esses ditames porque justamente vão de encontro as suas características mais primordiais: a dominância, por parte do homem, e a submissão, por parte da mulher. Sendo assim, aqui se apresenta um dos maiores problemas - e via de entrada para aqueles em busca de desmoroná-los - dos ditames de gênero: "o fato de alguém ser representado ou se representar como masculino ou feminino subentende a totalidade daqueles atributos (LAURETIS, 1994, p. 212)". 
Por fim, ao endereçar a questão da sexualidade, trazemos as palavras de Figueiredo (2013):

Quando uma mulher acumula parceiros, é tachada de ninfomaníaca, o que remete a doença mental, a ideia de obsessão, de insatisfação permanente, de anormalidade. No entanto, quando se trata do homem, o termo empregado é donjuanismo, o que remete a conquistador, viril, potente. A quantidade é domínio do masculino, à mulher está reservada a fidelidade a um parceiro ou a prostituição, que tem seu lado venal, o que é confirmado pelas narrativas de garotas de programa (FIGUEIREDO, 2013, p. 103, grifo nosso).

Ao analisarmos as narrativas de personagens como Joe e Glauco, ambos com uma vida sexualmente ativa - uma inclusive carregando o título de ninfomaníaca -, assumpções como as levantadas pela autora são levadas em consideração. $O$ intuito disso sendo o de enaltecer o modo como a narrativa desses personagens desconstrói essa pesada e complexa construção que uma sociedade guiada pela binaridade alicerçou sobre termos como "ninfomaníaca" e "donjuanismo". Decisões feitas por Joe em muito se assemelham ao que seria tomado como costumeiro se desempenhado por um homem, enquanto que Glauco, apesar de narrar diversas relações sexuais próprias, muito do que se vê atrelado ao "donjuanismo" se perde na narrativa desse masoquista, enuviando, assim, a conexão, antes direta, entre tal termo e as ideias de virilidade e conquista, visto que seu objetivo é ser conquistado e subjugado por seus parceiros, pois é nessa diferença que reside o seu verdadeiro prazer.

\section{Análise e comparação}

A seguir, analisaremos excertos de alguns sonetos presentes em Pegadas Noturnas (2004) e passagens do filme Ninfomaniaca (2014), para, a partir deles, comparar as narrativas de Joe e Glauco. Selecionamos, portanto, como foco dessa análise, passagens que compreendem os seguintes traços e/ou momentos da narrativa desses personagens: sua iniciação sexual ou descoberta da sexualidade, o papel que desempenham no ato sexual, e o momento de aceitação dessa sexualidade.

\subsection{Iniciação ou descoberta da sexualidade}

No que concerne ao momento de iniciação sexual para o personagem Glauco 
Mattoso, tomamos como objeto de análise o seguinte soneto, em sua integridade:

\section{Autobiográfico}

Um fato me marcou pra toda a vida: aos nove anos fui vitima dos caras mais velhos, que brincavam com as taras, levando-me da escola pra avenida.

Curravam-me num beco sem saída, zoavam inventando coisas raras, como lamber sebinho em suas varas e encher a minha boca de cuspida.

O que dava mais nojo era a poeira da sola dos seus tênis, misturada com doce, pão, cocô ou xepa de feira.

O gosto do solado e da calçada na língua fez de mim, queira ou não queira, a escória dos podólatras, mais nada.

(MATTOSO, 2004, p. 33)

Em "Autobiográfico", podemos observar o momento no qual o personagem Glauco entra em contato coma experiência que viria a the abrir os olhos para o fetiche que carregava consigo e do qual ainda não havia se dado conta. No decorrer do soneto, é atacado por garotos mais velhos que, ao que parece, eram alunos da mesma escola a que ele, com nove anos, comparecia. Os mesmos, segundo o eu lírico do personagem, brincavam com as taras e, levando-o até um beco sem saída, abusaram do mesmo, obrigando-o a realizar felação e receber em sua boca cuspidas e, por fim, o solado de seus sapatos. Esse último, porém, foi o favorito de Glauco, pois carregava consigo um misto de gostos saborosos e nojentos: "doce, pão, cocô e xepa de feira".

Nos textos canônicos escritos por homens, a personagem feminina deve passar por um processo de iniciação, como se ela fosse incapaz de descobrir sua sexualidade sem a orientação e a direção dos homens. A partir do momento em que ela libera sua libido, tornase personagem central, servindo ao projeto fálico do homem [...] (FIGUEIREDO, 2013, p. 101).

Portanto, a partir do que é trazido por Figueiredo (2013), identificamos que o "ritual" de iniciação à vida sexual transfigurado por Mattoso em poesia autobiográfica em muito se assemelha ao que, em textos canônicos, acontecia a personagens 
femininas. Logo, Glauco, como personagem, acaba por ocupar uma posição de submissão e dependência em relação ao parceiro do sexo masculino, o que é geralmente desempenhado por indivíduos do gênero feminino. No caso de Joe, observaremos na passagem a seguir, que há, assim como em Glauco, uma inversão de papéis nesse cenário pré-estipulado:

Eu descobri minha vagina quando tinha dois anos de idade. Ainda pequena [...] quando tínhamos Educação Física, eu subia na corda e ficava lá por horas com a corda no meio das minhas pernas. Nós chamávamos isso de "A Sensação" (NINFOMANÍACA, 2014, tradução nossa).

Ao descobrir sua vagina aos dois anos, além de iniciar qualquer contato de cunho sexual mais cedo do que Glauco, Joe ainda o tem consigo mesma, sem necessitar do apoio masculino para ser iniciada. Alguns anos mais tarde, a mesma toma controle dessa sexualidade ao incitar "A Sensação" durante as aulas de Educação Física, referência direta à masturbação, que se desempenhada por garotos em uma idade tenra, não costuma receber tanta discriminação quanto quando é efetuada por garotas ainda jovens. Sendo assim, Joe desconstrói posições pré-estabelecidas para mulheres, tais como a da castidade ou da ideia de que a "sexualidade reduzida à genitalidade se apresenta para as mulheres como algo sujo, vergonhoso, proibido" (CABRAL E DÍAZ, 1998, p. 1).

\subsection{Papel desempenhado nas relações sexuais}

Em nossa sociedade atual, "a construção sexista "masculino/feminino" coloca evidentemente o primeiro elemento em superioridade, propagando a noção simplista de "homem dominante versus mulher dominada (SCHULTZ, 2011 p. 3)". Nos excertos dos sonetos "Estudantil" e "Desvirtuado", de Glauco Mattoso, e nas passagens do longa-metragem Ninfomaníaca (2014) apresentadas na sequência, podemos observar que essa "verdade absoluta" não se vê presente na estruturação das narrativas dos personagens Glauco e Joe.

Estudantil

Calouro disfarçado, fui tratado que nem um bicho, a chute, "Xô!" e chicote, lambendo o veterano pé suado.

É claro que não fiz nenhum fricote! 
Assim é que eu queria ser usado! Fui eu quem lhes passou o maior trote! (MATTOSO, 2004, p. 55)

Desvirtuado

Tratar mulher a relho é uma delícia somente comparável ao pudim de leite condensado ou à carícia

da língua sobre o pênis. Quanto a mim, Sonhei que, atrás das grades da polícia, a nata dos ladrões me trata assim... (MATTOSO, 2004, p. 105)

Ao trazer nos excertos acima dois tipos de indivíduos, mais especificamente veteranos e ladrões, o personagem Glauco Mattoso impõe a si mesmo a posição de submissão em relação a eles. Vista, majoritariamente, como uma posição difamadora para indivíduos do gênero masculino, a submissão é aqui afiliada por Mattoso a sensações boas e recompensantes. Em "Estudantil", ao entrar de penetra num trote estudantil, o eu lírico do personagem insinua que aqueles que realmente receberam o trote foram seus "torturadores", pois, ao tratá-lo de maneira brusca e obrigarem-no a lamber seus pés, o forneceram justamente o que desejava. Já em "Desvirtuado", através de uma correlação direta entre si e as mulheres submissas sexualmente, Glauco deseja tomar seu lugar e ter como algozes a nata de ladrões que se encontram atrás das grades, outro momento no qual, através da submissão, traço dito feminino, ele alcança o que deseja.

Eu estava na casa da minha amiga B. Nós vestimos roupas que viriam a ser chamadas 'roupas fode-me agora'. A ideia era fazer uma competição. Nós tínhamos de embarcar numa viagem de metrô. B disse que [...] aquela que tivesse fudido mais homens quando chegássemos na última parada ganharia um saquinho de doces (NINFOMANÍACA, 2014, tradução nossa).

B e eu criamos um clube chamado "O Pequeno Rebanho". [...] A mensagem era endereçada aos homens. Era sobre foder e sobre ter o direito de ficar excitada. Nós nos masturbávamos juntas [...] mas era rebelde. Nós não podíamos ter namorados. Não podíamos fuder com o mesmo cara mais de uma vez. [...] Nós desejávamos combater essa sociedade baseada no amor (NINFOMANÍACA, 2014, tradução nossa).

Situações consideradas costumeiras quando desempenhadas por um garoto 
adolescente, tais como sair com amigos em busca de garotas com as quais possam transar e, muitas das vezes, também colecionar um número grande desses casos amorosos ou transas casuais, são, nas passagens em questão, desempenhadas pela personagem Joe. Ao se unir à sua amiga $B$, as duas transformam o sexo, geralmente considerado algo que, para as meninas, deve acontecer com alguém especial, em um simples jogo.

Porém, como a mesma afirma, esse jogo carrega consigo uma mensagem, uma crítica a uma sociedade que as retirou o direito de se sentirem excitadas e de, assim como os garotos, terem prazer no ato sexual. A sociedade que consideram baseada no amor se assemelha muito a ideia de sexo que é instruída às garotas, e a atitude que as duas tomam ao formar "O Pequeno Rebanho", mais uma vez, denota o objetivo dessa personagem em desconstruir e esticar o molde ao qual deveria se encaixar,abrindo espaço para os seus desejos.

\subsection{Aceitação da sexualidade}

Glauco Mattoso, um personagem que carrega consigo as máculas dos adjetivos "masoquista" e "podólatra" - práticas sexuais abominadas pela sociedade, seja por parecem nojentas ou estranhas para muitos, seja por fugirem do que é convencionalmente reconhecido como normal - é um exemplo de resistência ao que é pré-estabelecido, ao ordenar de estereótipos com os quais os indivíduos devem conformar-se, sendo que ao surgir de qualquer incongruência frente ao esperado, são logo tachados de "doentes" ou "anormais".

Porém, acerca do masoquismo, se retomarmos seus primórdios, se torna muito intrigante "o fato de a moral moderna ter atribuído tão fortemente o masoquismo às mulheres quando nos textos de Sacher-Masoch, e em boa medida também nos textos do Marques de Sade, os homens são na maior parte das vezes os masoquistas e as mulheres são as sádicas (FONSECA, 2010, p. 146)". Sendo assim, com o intuito de tratar do que seria o "normal" e identificar o momento de aceitação do personagem Glauco Mattoso, trazemos o soneto a seguir:

Nojento

Tem gente que censura o meu fetiche: lamber pé masculino e o seu calçado. Mas, só de ver no quê o povo é chegado, não posso permitir que alguém me piche. 
Onde é que já se viu ter sanduíche de fruta ou vegetal mal temperado? E pizza de banana? E chá gelado? Frutos do mar? Rabada? Jiló? Vixe!

Café sem adoçar? Feijão sem sal? Rã? Cobra? Peixe cru? Lesma gigante?

Farofa de uva passa? Isso é normal?

Quem gosta disso tudo não se espante com minha preferência sexual: lamber o pé e o pó do seu pisante." (MATTOSO, 2004, p. 25)

Desenvolvendo um jogo de comparação recheado de sarcasmo, Glauco Mattoso monta "Nojento" com o objetivo de questionar o porquê de rechaçarem seu fetiche, afinal, não entende como outros podem implicar tanto com seu gosto, se se permitem degustar coisas que, do ponto de vista do eu lírico desse personagem, são tão nojentas quanto. Glauco, inclusive, Ihes devolve o questionamento: "Isso é normal?" Fazendo uso do que the é característico, a poesia satírico-fescenina, Mattoso desenvolve uma maneira de demonstrar que não mais se recusa a aceitar suas preferências, pois, no fim do dia, todos nós temos nossos gostos "asquerosos", sejam eles revelados na cozinha ou entre quatro paredes.

Pensando na passagem que, na sequência, servirá de modo a identificarmos o momento de aceitação, por parte de Joe, de sua ninfomania, trazemos, para costurar um contraponto, os dizeres de Figueiredo (2013):

Claire, uma personagem de Virginie Despentes, afirma que as mulheres casadas, "normais" como ela, gostavam dos momentos de sexo, gostavam de sentir que o homem tinha prazer e que esse prazer passava por elas. Isso seria, segundo ela, o verdadeiro gozo feminino. Só as mulheres, as ninfomaníacas, buscariam o orgasmo. (FIGUEIREDO, 2013, p. 104).

Assim como durante sua iniciação sexual, vemos que a mulher é apresentada novamente como um catalisador que funciona em função do ser masculino. Antes iniciada por ele, a mulher é agora considerada "anormal" se não participa do ato sexual em busca de um orgasmo que receberá ao causar o gozo de seu amante. Resta, portanto, àquelas que buscam o orgasmo próprio o título de "ninfomaníacas".

Caríssimas, não achem que tem sido fácil, mas eu entendo agora que nós não somos, nem nunca seremos, iguais. Eu não sou como vocês, que fodem para serem validadas e, portanto, podem desistir 
de terem paus dentro de suas vaginas. Não sou como vocês. Tudo que vocês querem é estarem preenchidas, seja por um pênis ou pelas porcarias que comem, não faz diferença alguma. Eu definitivamente não sou como vocês. A empatia que vocês dizem ter é uma mentira, porque vocês são, simplesmente, a polícia da moralidade à serviço da sociedade cujo trabalho é apagar a minha obscenidade da face da terra para que a burguesia não se enoje. Não sou como vocês. Eu sou uma ninfomaníaca e me amo por isso. Mas, acima de tudo, eu amo minha vagina e minha luxúria nojenta e suja (NINFOMANÍACA, 2014, tradução nossa).

Agarrando-se aos mais arraigados traços de nossa cultura mundial, Joe traz à tona questões como o sexo em busca de validação - cujo construto original reside na questão supracitada do orgasmo feminino ser apenas um resultado do masculino, partindo dele assim como Eva surgiu da costela de Adão - e o apagar da obscenidade - o que, até mesmo, se vê evidenciado no fato de um longa-metragem como Ninfomaníaca (2014) receber reconhecimento por seu conteúdo integral, ao invés de ser rechaçado por seu conteúdo visual explícito e "obsceno".

Por último, Joe dá vazão à sua liberdade quando aceita que não é como as outras mulheres que a circundam, "viciadas em sexo" que querem libertar-se dessa vida errônea, pois chega à conclusão de que não odeia, nem deseja descartar, esse traço de sua personalidade. Ser uma ninfomaníaca e não deixar que o peso dessa palavra lhe assuste é o que permite que Joe descontrua muito do que se ergueu em torno do que é ser mulher e do que significa ser sexualizada. Dessa vez, por si mesma, sem deixar que seu sexo sirva de catalisador ao prazer alheio.

\section{Conclusão}

"Tarados também têm tons variados", diz Glauco Mattoso em um de seus sonetos, o que encapsula muito do que pretendíamos trazer com a escrita desse artigo. Seja na voz de Glauco, seja na de Joe, ambos desajustados frente à uma sociedade que os vê como anormais, excluindo-os, identificamos uma força e persistência que não querem se apagar.

Suas narrativas, uma disposta sobre o título de "marginal", a outra sobre o de "pornográfica", são muitas vezes barradas ou rechaçadas pela sociedade.O choque de ler um poema ou assistir a um filme que contêm cenas de sexo explícito, vocabulário chulo ou descrições gráficas de cenas tidas como escatológicas previne, muitas vezes, um leitor de entrar em contato com uma obra atemporal e desafiadora 
para a conjuntura da sociedade atual.

Perde-se, ao negar, hipocritamente, a veracidade crua desses textos, a chance de se experienciar uma quebra dos valores mais enrijecidos e cristalizados de nossa sociedade. Um grito de guerra que, trazido das margens, atinge em cheio os muros engessados de uma sociedade que deixou de pensar além do que já se estipulou e fez-se lei.

\section{REFERÊNCIAS}

BOSI, Alfredo. Literatura e resistência. São Paulo: Companhia das Letras, 2002.

CABRAL, F.; DÍAZ, M. Relações de gênero. In: SECRETARIA MUNICIPAL DE EDUCAÇÃO DE BELO HORIZONTE; FUNDAÇÃO ODEBRECHT. Cadernos afetividade e sexualidade na educação: um novo olhar. Belo Horizonte: Gráfica Editora RonaLtda, 1998. p. 142-150.

CAIXETA, Ana Paula Aparecida; RICHARD, Rosimara. Conversando com Glauco Mattoso: o processo criativo do escritor maldito. Uniletras, Ponta Grossa, v. 36, n. 2, p. 235-248, jul/dez. 2014.

FIGUEIREDO, Eurídice. Mulheres ao espelho: autobiografia, ficção, autoficção. Rio de Janeiro: EdUERJ, 2013.

FONSECA, Felipe Lessa da. O masoquismo masculino nos sujeitos: a repetição inconsciente. São Paulo: PUC-SP, 2010.

LAURETIS, Teresa de. As tecnologias do gênero. In: HOLLANDA, Heloísa Buarque de. (Org.) Tendências e impasses: o feminismo como crítica da cultura. Rio de Janeiro: Rocco, 1994. pp. 206-242.

MAINGUENEAU, Dominique. O discurso pornográfico. São Paulo: Parábola Editorial, 2010.

MATTOSO, Glauco. O que é poesía marginal. São Paulo: Brasiliense, 1981.

MATTOSO, Glauco. Pegadas noturnas. São Paulo: Lamparina Editora, 2004.

NYMPHOMANIAC. Direção: Lars Von Trier. Dinamarca: Zentropa Entertainments, 2014.

PINTO, Manuel da Costa. Glauco Mattoso. In: Literatura Brasileira Hoje. São Paulo: Publifolha, 2010.

PITTA, Ana Lúcia. Feminilidade, grotesco e maldição: Análise do filme Anticristo de Lars Von Trier. UFJF, Juiz de Fora. 2014.

SCHULTZ, Leonardo. O lampião da esquina: discussões de gênero e sexualidade no Brasil no final da década de 1970. Paraná: Universidade Positivo, 2011. 
